\title{
PENGARUH PEMAKAIAN PERASAN AKAR RUMPUT ALANG-ALANG SEBAGAI HAND SANITIZER TERHADAP ANGKA KUMAN TANGAN CLEANING SERVICE
}

\author{
Rizki Amalia Putri' ${ }^{1)}$, Djamaluddin Ramlan ${ }^{1)}$, Khomsatun ${ }^{1)}$ \\ Poltekkes Kemenkes Semarang
}

\begin{abstract}
Abstrak
Akar rumput alang-alang (imperata cylindrica) mengandung senyawa yang dapat berfungsi sebagai anti mikroba yaitu golongan triterpenoid diantaranya cylindrin, arundoin, ferneon, isoarborinol, dan sikiarenol. Tujuan penelitian ini adalah menemukan cara membersihkan tangan dari kuman menggunakan handsanitizer berbahan akar rumput alang-alang. Jenis penelitian yang dipakai adalah penelitian pre experiment dengan rancangan pre test dan post test design. Analisis statistik yang digunakan Paired T-Test dan Anova One Way. Metode penelitian dengan cara pemeriksaan angka kuman tangan sebelum dan sesudah menggunakan handsanitizer berbahan akar rumput alangalang. Handsanitizer perasan akar rumput alang-alang dengan dosis yang berbeda yaitu dosis $5 \mathrm{ml}$, dosis $10 \mathrm{ml}$ dan dosis $15 \mathrm{ml}$. Hasil uji Paired T-Test dosis $5 \mathrm{ml}$ secara statistik tidak ada pengaruh yang signifikan $(\mathrm{p}=0,767$ atau $\mathrm{p}>0,05)$. Dosis $10 \mathrm{ml}$ secara statistik tidak ada pengaruh yang signifikan ( $\mathrm{p}=0,919$ atau $\mathrm{p}>0,05)$. Dosis $15 \mathrm{ml}$ secara statistik tidak ada pengaruh yang signifikan $(\mathrm{p}=0,847$ atau $\mathrm{p}>0,05)$. Dari ketiga dosis tersebut setelah di uji menggunakan uji Anova menunjukan nilai $\mathrm{p}$ (sig) 0,539 . Kesimpulan penelitian ini adalah tidak ada pengaruh pemakaian perasan akar rumput alang-alang sebagai handsanitizer terhadap penurunan angka kuman. Saran bagi peneliti selanjutnya sebaiknya menurunkan dosis perasan akar rumput alang-alang agar lebih efektif dalam menurunkan angka kuman pada tangan.
\end{abstract}

Kata kunci : rumput alang-alang, handsanitizer, angka kuman tangan

\begin{abstract}
Imperata cylindrical grassroots contains compounds that can function as anti microbial which is triterpenoid group with cylindrin, arundoin, ferneon, isoarborinol, and sikiarenol. The purpose of this research is to find a way to clean hand from germs by using handsanitizer made from imperata cylindrical grassroots. Theresearch type used is pra-experiment research with pra-test design and post test design. the statistic analysis used is Paired T-Test and Anova One Way. The research method is by the inspection of the number of hand germs before and after using handsanitizer made from imperata cylindrical grassroots. Handsanitizer made from imperata cylindrical grassroots squeeze with different dosages which are $5 \mathrm{ml}$ dosages, $10 \mathrm{ml}$ dosages, and 15 $\mathrm{ml}$ dosages. Paired T-Test test results of $5 \mathrm{ml}$ dose were statistically no significant effect $(p=0.767$ or $p>0.05)$. The $10 \mathrm{ml}$ dose was statistically no significant effect $(p=0.919$ or $p>0.05)$. A $15 \mathrm{ml}$ dose was not statistically significant ( $p=0.847$ or $p>0.05$ ). From thatthree dosages after tested by using Anova One Way test shows that the p value (sig) 0,539. The conclusion of this research is that there is no effect of imperata cylindrical grassroots squeeze usage as handsanitizer to decrease the number of germs. Suggestions for future researchers should be to reduce the juice dosage of Imperata grass roots to be more effective in reducing the number of germs in the hand.
\end{abstract}

Keywords : imperata cylindrical grass, handsanitizer, number of hand germs 


\section{Pendahuluan}

Berdasarkan ketentuan dalam Peraturan Pemerintah Nomor 66 Tahun 2014 tentang Kesehatan Lingkungan, Kesehatan Lingkungan adalah upaya pencegahan penyakit dan atau gangguan kesehatan dari faktor risiko lingkungan untuk mewujudkan kualitas lingkungan yang sehat baik dari aspek fisik, kimia, biologi maupun sosial.

Pada Peraturan Menteri Kesehatan Nomor 3 Tahun 2014 tentang Sanitasi Total Berbasis Masyarakat (STBM), dalam rangka memperkuat upaya perilaku hidup bersih dan sehat, mencegah penyebaran penyakit berbasis lingkungan, meningkatkan kemampuan masyarakat, serta meningkatkan akses air minum dan sanitasi dasar, perlu menyelenggarakan Sanitasi Total Berbasis Masyarakat. Sanitasi Total Berbasis Masyarakat berpedoman pada Pilar Sanitasi Total Berbasis Masyarakat. Pilar Sanitasi Total Berbasis Masyarakat yang dimaksud terdiri atas perilaku Stop Buang Air Besar Sembarangan, Cuci Tangan Pakai Sabun, Pengolahan Air Minum dan Makanan Rumah Tangga, Pengamanan Sampah Rumah Tangga, dan Pengamanan Limbah Cair Rumah Tangga. Cuci tangan pakai sabun yang berfungsi untuk membersihkan tangan dan membunuh kuman pada tangan. Namun, saat air dan sabun tidak tersedia, hand sanitizer bisa menjadi alternatif utama untuk cuci tangan. Seiring dengan berkembangnya jaman banyak sekali produk-produk instan yang serba cepat dan praktis, maka muncul produk inovasi pembersih tangan tanpa air yang dikenal dengan pembersih tangan antiseptik atau hand sanitizer. Hand sanitizer antiseptik yang sering digunakan adalah alkohol. Alkohol telah digunakan secara luas sebagai obat antiseptik kulit karena mempunyai efek menghambat pertumbuhan bakteri ( Fajar Ardi Desiyanto, 2013)

Handsanitizer juga bisa berbahan organik yang memiliki kandungan yang dapat merusak dinding sel bakteri. Salah satu bahan organik seperti akar rumput alang-alang, bisa di gunakan sebagai bahan handsanitizer karena mengandung komposisi kimia yang bisa dijadikan anti mikroba. Jayalakshmi, et al (2011) menyebutkan bahwa akar alangalang mengandung senyawa yang dapat berfungsi sebagai anti mikroba yaitu golongan triterpenoid diantaranya cylindrin, arundoin, ferneon, isoarborinol dan simiarenol.

Saponin merupakan senyawa dalam bentuk glikosida yang tersebar luas pada tumbuhan dan menimbulkan busa bila dikocok dengan air. Beberapa saponin bekerja sebagai anti mikroba. Saponin memiliki 2 jenis yaitu, glikosida triterpenoid dan glikosida struktur steroid. Mekanisme Triterpenoid sebagai anti bakteri adalah bereaksi dengan porin diluar dinding sel bakteri, membentuk ikatan polimer yang mengakibatkan porin rusak. Porin rusak sebagai pintu masuknya senyawa dan akan mengurangi permeabilitas membran sel bakteri yang mengakibatkan sel bakteri kekurangan nutrisi, sehingga pertumbuhan bakteri terhambat atau mati (Rachmawati, dalam Syafiq, 2015).

Pada penelitian yang dilakukan oleh Raka Novadlu Cordita (2017) terdapat perbedaan jumlah angka kuman sebelum dan sesudah mencuci tangan menggunakan handsanitizer dan sabun antiseptik.

Tujuan penelitian adalah Menemukan cara membersihkan tangan dari kuman menggunakan handsanitizer berbahan akar rumput alang-alang.

\section{Bahan dan Metode}

Pengambilan sampel dilakukan pada Cleaning Service di kampus VII Poltekkes Kemenkes Semarang, pemeriksaan angka kuman dilakukan di Laboratorium Kesehatan Daerah Purbalingga jalan Letkol Isdiman No.5, Purbalingga. Penelitian dilaksanakan pada 19 maret - 21 maret 2019.

Jenis penelitian ini adalah Pre eksperimen dengan desain penelitian pre test and post test design. Jumlah sampel dalam penelitian 3 clening service. Pengukuran angka kuman dilakukan dengan metode usap tangan yang dilakukan selama 3 hari sebagai replikasi. Pengukurn dilaksanakan pada pukul 11.00 WIB - 12.00 WIB. Pemeriksaan dilakukan di 3 tempat mengikuti aktivitas cleaning service. Analisis yang digunakan dalam penelitian ini adalah analisis uji Paired T-Test dan Anova One Way

\section{Hasil dan Pembahasan}

\section{A. Data Umum}

Petugas cleaning service adalah orang yang bertanggung jawab dalam tugas pemeliharaan dan pelayanan kebersihan di suatu tempat baik institusi pemerintah maupun swasta. Secara umum petugas cleaning service di Kampus VII Poltekkes Kemenkes Semarang memliki tugas membersihkan halaman atau lingkungan kampus yang ada di area kampus, seperti menyapu halaman, potong rumput dan membersihkan bagian yang kotor, mengolah sampah dan mengangkut sampah yang ada 
disekitar kampus. Namun petugas tidak selalu mendapatkan tugas yang sama setiap harinya, dikarenakan adanya tugas tambahan seperti membantu menyiapkan auditorium untuk keperluan acara. Aktivitas yang dilakukan oleh petugas cleaning service akan mempengaruhi hasil angka kuman. Semakin padatnya aktivitas yang dilakukan akan mempengaruhi jumlah angka kuman yang ada di tangan. Tangan merupakan jalur utama masuknya kuman penyakit dalam tubuh. Petugas cleaning service menghabiskan waktunya sepanjang hari di lingkungan pekerjaan, berbagai macam aktivitas cleaning service membuat cleaning service lebih mudah terpapar berbagai bentuk bakteri. Kurangnya kesadaran cleaning service dalam menggunakan sarung tangan karena di tempat kerja tidak selalu tersedia sarung tangan untuk digunakan pada saat bekerja. Cleaning service harus memakai sarung tangan untuk menjaga tangannya agar terbebas dari kuman ketika bekerja. Terutama pada saat bekerja di bank sampah, memilah dan mengolah sampah. Tangan cleaning service akan bersinggungan dengan tanah dan berbagai macam jenis sampah yang ada, tanah yang disentuh bisa jadi sudah terkontaminasi oleh bibit penyakit. Jika cleaning service tidak menggunakan sarung tangan dan mencuci tangan setelah bekerja maka akan rentan terkena infeksi dari serangan kuman atau bakteri penyakit.

\section{B. Hasil Riset}

Pengambilan sampel dilakukan pada tanggal 19 Maret 2019 - 21 Maret 2019 pukul $11.00-12.00$ WIB di 3 tempat yaitu, laboratorium vektor, gedung $\mathrm{E}$, dan Bank Sampah. Penelitian dilakukan di Kampus VII Poltekkes Kemenkes Semarang, dengan subyek penelitian 3 orang cleaning service. Sampel usap telapak tangan diambil dari telapak tangan kanan cleaning service. Pengambilan sampel usap telapak dilakukan sebelum menggunakan handsanitizer dan sesudah menggunakan handsanitizer. Metode pencucian tangan sesuai dengan prosedur cuci tangan menurut rekomendasi ari WHO yakni 6 langkah cuci tangan yang baik dan benar.

\section{Analisis Data}

1. Analisis Univariat

a. Hasil Pemeriksaan Angka Kuman pada tangan Cleaning Service Sebelum dan Sesudah menggunakan Handsanitizer dari perasan akar rumput alang-alang

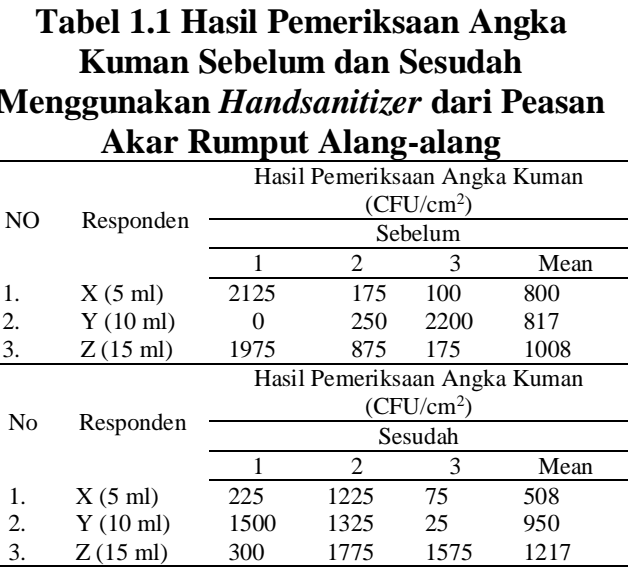

Pemeriksaan angka kuman sebelum menggunakan Handsanitizer yang paling tinggi adalah Y replikasi pertama yaitu 2200 $\mathrm{CFU} / \mathrm{cm}^{2}$. Pemeriksaan angka kuman sesudah menggunakan Handsanitizer yang paling tinggi adalah $\mathrm{Z}$ replikasi kedua yaitu 1775 $\mathrm{CFU} / \mathrm{cm}^{2}$. Pemeriksaan angka kuman sebelum menggunakan Handsanitizer yang paling rendah adalah $\mathrm{Y}$ replikasi pertama yaitu $0 \mathrm{CFU} / \mathrm{cm}^{2}$. Pemeriksaan angka kuman sesudah menggunakan Handsanitizer yang paling rendah adalah $\mathrm{Y}$ replikasi ketiga yaitu $25 \mathrm{CFU} / \mathrm{cm}^{2}$.

Hasil pemeriksaan angka kuman pada tangan responden sebelum penggunaan handsanitizer memiliki rata - rata tertinggi $1008 \mathrm{CFU} / \mathrm{cm}^{2}$ pada responden $\mathrm{Z}$ dan rata rata terendah $800 \mathrm{CFU} / \mathrm{cm}^{2}$ pada responden $X$. Hasil pemeriksaan angka kuman pada tangan responden setelah penggunaan handsanitizer memiliki rata - rata tertinggi $1217 \mathrm{CFU} / \mathrm{cm}^{2}$ pada responden $\mathrm{Z}$ dan ratarata terendah $508 \mathrm{CFU} / \mathrm{cm}^{2}$ pada responden $\mathrm{X}$.

Tabel 1.2 Selisih Angka Kuman Sesudah dan Sebelum Menggunakan Handsanitizer dari Perasan Akar Rumput Alang-alang

\begin{tabular}{cccccc}
\hline \multirow{2}{*}{ NO } & \multirow{2}{*}{ Responden } & \multicolumn{4}{c}{ Selisih Sesudah dan Sebelum } \\
\cline { 3 - 6 } & & \multicolumn{1}{c}{1} & 2 & 3 & Mean \\
\hline 1. & $\mathrm{X}(5 \mathrm{ml})$ & -1900 & 1050 & -25 & -292 \\
2. & $\mathrm{Y}(10 \mathrm{ml})$ & 1500 & 1075 & -2175 & 133 \\
3. & $\mathrm{Z}(15 \mathrm{ml})$ & -1975 & 900 & 1400 & 209 \\
\hline
\end{tabular}

Handsanitizer dosis $5 \mathrm{ml}$ pada replikasi pertama mengalami penurunan sebesar -1900 $\mathrm{CFU} / \mathrm{cm}^{2}$. Tanda (-) artinya penurunan. Hal tersebut terjadi karena responden tersebut memiliki antusias yang tinggi untuk memperhatikan peneliti pada saat memberikan penjelasan tentang tata cara menggunakan handsanitizer. Pada replikasi kedua mengalami penaikan sebesar 1050 $\mathrm{CFU} / \mathrm{cm}^{2}$. Hal tersebut terjadi karena responden memiliki tangan yang tidak kering atau basah. Menurut Hand hygiene europe, 
(2012) dalam Retno, (2016) h.15 tangan basah menyebarkan kuman 1000 kali lebih banyak dari pada tangan kering. Pada replikasi ketiga mengalami penurunan sebesar -25 $\mathrm{CFU} / \mathrm{cm}^{2}$. Hal tersebut terjadi karena responden pada hari tersebut aktivitas nya hanya memegang alat yang digunakan untuk memilah sampah, sehingga angka kuman yang dihasilkan tidak terlalu banyak.

Handsanitizer dosis $10 \mathrm{ml}$ yang diperlakukan pada responden Y memiliki hasil pada replikasi pertama mengalami penaikan sebesar $1500 \mathrm{CFU} / \mathrm{cm}^{2}$. Hasil pemeriksaan sebelum menggunakan handsanitizer hasil angka kumannya 0 $\mathrm{CFU} / \mathrm{cm}^{2}$, hal tersebut secara logika tidak logis karena responden sebelumnya tidak mencuci tangannya dengan apapun, kemungkinan hal tersebut terjadi karena kesalahan hasil pemeriksaan. Pada replikasi kedua mengalami penaikan sebesar 1075 $\mathrm{CFU} / \mathrm{cm}^{2}$. Hal tersebut terjadi karena responden $\mathrm{Y}$ diluar pengawasan peneliti responden melakukan aktivitas lain sehingga memungkinkan angka kuman bertambah banyak. pada replikasi ketiga mengalami penurunan sebesar $-2175 \mathrm{CFU} / \mathrm{cm}^{2}$. Hal tersebut terjadi karena responden $\mathrm{Y}$ melakukan langkah-langkah menggunakan handsanitizer dengan baik, dan kadar yang sesuai dengan kebutuhan tangannya sehingga pada saat di usap tangannya setelah menggunakan handsanitizer hasil angka kumannya turun.

Handsanitizer dosis $15 \mathrm{ml}$ yang diperlakukan pada responden $\mathrm{Z}$ memiliki hasil pada replikasi pertama mengalami penurunan sebesar $-1675 \mathrm{CFU} / \mathrm{cm}^{2}$. Hal tersebut terjadi karena responden $\mathrm{Z}$ melakukan langkah-langkah menggunakan handsanitizer dengan baik, dan kadar yang sesuai dengan kebutuhan tangannya sehingga pada saat di usap tangannya setelah menggunakan handsanitizer hasil angka kumannya turun. Pada replikasi kedua mengalami kenaikan sebesar $900 \mathrm{CFU} / \mathrm{cm}^{2}$. Hal tersebut terjadi karena responden $\mathrm{Z}$ memiliki luas tangan yang luas, memungkinkan responden menuangkan handsanitizer kurang banyak, tidak menyebar keseluruh permukaan dan sela - sela jari sehingga angka kuman bisa bertambah karena peneliti mengusap sampai sela - sela jari. Pada replikasi ketiga mengalami kenaikan sebesar $1400 \mathrm{CFU} / \mathrm{cm}^{2}$. Hal tersebut terjadi karena responden $\mathrm{Z}$ diluar pengawasan peneliti responden melakukan aktivitas lain sehingga memungkinkan angka kuman bertambah banyak. b. Efektivitas variasi dosis terhadap penurunan angka kuman pada tangan

Sesudah perlakuan - sebelum perlakuan $\times 100 \%$

Sebelum perlakuan

Efektivitas variasi dosis di dapatkan dari hasil sesudah perlakuan di kurangi hasil sebelum perlakuan di bagi dengan hasil sebelum perlakuan kemudian di kali $100 \%$

Tabel 1.3 Efektivitas Variasi Dosis Perasan Akar Rumput Alang-alang dalam Menurunkan Angka Kuman pada Tangan

\begin{tabular}{cccc}
\hline $\begin{array}{c}\text { No } \\
\cdot\end{array}$ & Variasi Dosis & $\begin{array}{c}\text { Efektivitas Handsanitizer perasan akar } \\
\text { rumput alang-alang (Imperata cylindrica) } \\
(\%)\end{array}$ \\
\hline 1 & & 36,5 & \\
2 & $10 \mathrm{ml}$ & 16,27 & \\
3 & $15 \mathrm{ml}$ & 20,7 & \\
\hline & Dosis & yang paling efektivitas untuk
\end{tabular}
menurunkan angka kuman adalah dosis $5 \mathrm{ml}$, karena tingkat efektivitas nya paling besar dalam menurunkan yaitu 36,5\%. Sedangkan, dosis yang paling sedikit menurunkan adalah dosis $10 \mathrm{ml}$ yaitu nilai efektivitas nya sebesar 16,27\%. Dosis $5 \mathrm{ml}$ paling efektiv untuk menurunkan angka kuman karena pada komposisi handsanitizer dosis tersebut volume $\mathrm{H}_{2} \mathrm{O}_{2}$ lebih banyak dibandingkan dengan komposisi dosis yang lainnya. Dalam penelitian Retno Wuriyatmi (2016) handrub formula $^{\mathrm{RW}}$ mengandung $\mathrm{H}_{2} \mathrm{O}_{2}$ (Hidrogen Peroksida) 3\% yang merupakan jenis antiseptik yang sangat efektif dalam membunuh mikroorganisme atau kuman, penelitian tersebut sejalan dengan penelitian yang telah dilakukan dimana peneliti menggunakan $\mathrm{H}_{2} \mathrm{O}_{2} 3 \%$ tetapi dengan volume yang lebih banyak pada dosis $5 \mathrm{ml}$ sehingga efektifitas $\mathrm{H}_{2} \mathrm{O}_{2}$ lebih tinggi.

2. Analisis Bivariat

a. Hasil Analisis Paired T-Test Angka Kuman Sebelum dan Sesudah Perlakuan Handsanitizer Perasan Akar Rumput Alang-alang (Imperata cylindrica) dengan Dosis $5 \mathrm{ml}$, 10ml, dan $15 \mathrm{ml}$

Tabel 2.1 Hasil Analisis Paired T- Test Angka Kuman Sebelum dan Sesudah Perlakuan Handsanitizer Perasan Akar Rumput Alangalang (Imperata cylindrica) dengan Dosis $5 \mathrm{ml}$, $10 \mathrm{ml}$, dan $15 \mathrm{ml}$

\begin{tabular}{llllll}
\hline \multirow{2}{*}{ No } & \multirow{2}{*}{ Dosis } & \multicolumn{2}{c}{ Sebelum } & \multicolumn{2}{c}{ Sesudah } \\
\cline { 3 - 6 } & & Mean & SD & Mean & SD \\
\hline 1. & $5 \mathrm{ml}$ & 800 & 1148,09 & 508,33 & 625,16 \\
2. & $10 \mathrm{ml}$ & 816,66 & 1204,50 & 950 & 805,83 \\
3. & $15 \mathrm{ml}$ & 1008,33 & 907,37 & 1216,66 & 800,13 \\
\hline
\end{tabular}




\begin{tabular}{|c|c|c|c|}
\hline No & Dosis & $T$ & $P$ \\
\hline 1. & $5 \mathrm{ml}$ & 0,338 & 0,767 \\
\hline 2. & $10 \mathrm{ml}$ & 0.115 & 0,919 \\
\hline 3. & $15 \mathrm{ml}$ & 0,219 & 0,847 \\
\hline
\end{tabular}

Hasil analisis paired t-test digunakan untuk membuktikan apakah ada perbedaan yang bermakna atau tidak. Uji T dilakukan uji hipotesis untuk mengetahui apakah $\mathrm{Ha}$ diterima atau ditolak. Handsanitizer Perasan Akar Rumput Alang-alang (Imperata cylindrica) dengan dosis $5 \mathrm{ml}$ menunjukkan nilai koefisien $\mathrm{t}$ ( $\mathrm{t}$ hitung) sebesar 0,338 dengan nilai signifikan ( $\mathrm{p}_{\text {value }}$ ) $0,767>0,05$ $(\alpha=5 \%)$. Hasil analisis tersebut menunjukan tidak ada pengaruh pemakaian perasan akar rumput alang-alang (Imperata cylindrica) dengan dosis $5 \mathrm{ml}$ sebagai handsanitizer terhadap angka kuman tangan cleaning service, tetapi dilihat dari efisiensi nya dosis $5 \mathrm{ml}$ memiliki efisiensi yang tinggi dibandingkan dengan dosis yang lain

Pada Handsanitizer Perasan Akar Rumput Alang-alang (Imperata cylindrica) dengan dosis $10 \mathrm{ml}$ menunjukkan nilai koefisien $\mathrm{t}$ ( $\mathrm{t}$ hitung) sebesar -0,115 dengan nilai signifikan ( $\mathrm{p}$ value) $0,919>0,05(\alpha=$ $5 \%)$. Secara statistik hasil tersebut menunjukan tidak ada pengaruh pemakaian perasan akar rumput alang-alang (Imperata cylindrica) dengan dosis $10 \mathrm{ml}$ sebagai handsanitizer terhadap angka kuman tangan cleaning service.

Pada Handsanitizer Perasan Akar Rumput Alang-alang (Imperata cylindrica) dengan dosis $15 \mathrm{ml}$ menunjukkan nilai koefisien $\mathrm{t}$ ( $\mathrm{t}$ hitung) sebesar -0,219 dengan nilai signifikan ( $\mathrm{p}$ value $) 0,847>0,05(\alpha=$ $5 \%$ ). Hasil analisis tersebut menunjukan tidak ada pengaruh pemakaian perasan akar rumput alang-alang (Imperata cylindrica) dengan dosis $15 \mathrm{ml}$ sebagai handsanitizer terhadap angka kuman tangan cleaning service. Handsanitizer dari perasan akar rumput alang-alang tersebut dengan dosis yang berbeda beda tidak ada pengaruh nya dalam menurunkan angka kuman pada tangan cleaning service.

b. Hasil Analisis Anova Angka Kuman Sebelum dan Sesudah Perlakuan Handsanitizer Perasan Akar Rumput Alang-alang (Imperata cylindrica) dengan Dosis $5 \mathrm{ml}, 10 \mathrm{ml}$ dan $15 \mathrm{ml}$.
Tabel 2.2 Hasil analisis uji Anova angka kuman sebelum dan sesudah perlakuan handsanitizer perasan akar rumput alangalang (Imperata cylindrica)

\begin{tabular}{cccccc}
\hline & $\begin{array}{c}\text { Sum of } \\
\text { squares }\end{array}$ & df & $\begin{array}{c}\text { Mean } \\
\text { square }\end{array}$ & F & Sig \\
\hline $\begin{array}{c}\text { Between } \\
\text { grups }\end{array}$ & 767916,667 & 2 & $383958,333,685,539$ \\
$\begin{array}{c}\text { Within } \\
\text { groups }\end{array}$ & 3360833,333 & 6 & 560138,889 & \\
Total & 4128750,000 & 8 & & \\
\hline
\end{tabular}

Hasil uji statistik Anova One Way dapat dilihat pada tabel 4.14. Hasil diketahui nilai $\mathrm{p}(\mathrm{sig}) \quad 0,539$, pengambilan keputusan berdasarkan nilai $\mathrm{p}$ (sig) 0,539 , jika $\mathrm{p}>\alpha$ maka Ha ditolak artinya tidak ada pengaruh pemakaian perasan akar rumput alang-alang (imperata cylindrica) sebagai handsanitizer terhadap penurunan angka kuman antara ketiga dosis $(5 \mathrm{ml}, 10 \mathrm{ml}$, dan $15 \mathrm{ml})$, tetapi dilihat dari efisiensi nya dosis $5 \mathrm{ml}$ memiliki efisiensi yang tinggi dibandingkan dengan dosis yang lainnya, komposisi handsanitizer dosis tersebut volume $\mathrm{H}_{2} \mathrm{O}_{2}$ lebih banyak dibandingkan dengan komposisi dosis yang lainnya.

D. Kelemahan Peneelitian

Setelah melakukan penelitian ditemukan beberapa kelemahan dalam penelitian yaitu variabel kebersihan tangan yang ada pada variabel antara seharusnya masuk ke variabel kontrol, sebelum penelitian kebersihan tangan harus di kontrol untuk menghindari bertambahnya kuman.

\section{Kesimpulan dan Saran}

\section{A. Kesimpulan}

Berdasarkan hasil pembahasan penelitian dalam skripsi ini, maka dapat diambil

kesimpulan sebagai berikut :

1. Hasil angka kuman pada tangan sebelum menggunakan handsanitizer perasan akar rumput alang yaitu dosis $5 \mathrm{ml}$ rata rata angka kumannya sebesar $800 \mathrm{CFU} / \mathrm{cm}^{2}$, dosis $10 \mathrm{ml}$ rata rata angka kumannya sebesar $817 \mathrm{CFU} / \mathrm{cm}^{2}$, dan dosis $15 \mathrm{ml}$ rata rata angka kumannya sebesar 1008 $\mathrm{CFU} / \mathrm{cm}^{2}$.

2. Hasil angka kuman pada tangan sesudah menggunakan handsanitizer perasan akar rumput alang yaitu dosis $5 \mathrm{ml}$ rata rata angka kumannya sebesar $508 \mathrm{CFU} / \mathrm{cm}^{2}$, dosis $10 \mathrm{ml}$ rata rata angka kumannya sebesar $950 \mathrm{CFU} / \mathrm{cm}^{2}$, dan dosis $15 \mathrm{ml}$ rata rata angka kumannya sebesar 1217 $\mathrm{CFU} / \mathrm{cm}^{2}$ 
3. Efisiensi variasi dosis $5 \mathrm{ml}, 10 \mathrm{ml}$, dan $15 \mathrm{ml}$ terhadap penurunan angka kuman pada tangan adalah dosis $5 \mathrm{ml}$ memiliki nilai efisiensi yang paling tinggi sebesar $36,5 \%$.

4. Secara statistik dengan menggunakan uji Paired tidak ada pengaruh pemakaian perasan akar rumput alang alang (Imperata cylindrica) sebagai handsanitizer terhadap penurunan angka kuman tangan cleaning service. Dosisi 5 $\mathrm{ml}$ ( $\left.\mathrm{p}_{\text {value }}\right) 0,767>0,05(\alpha=5 \%)$. Dosisi $10 \mathrm{ml}$ ( $\mathrm{p}$ value) $0,919>0,05(\alpha=5 \%)$. Dosis $15 \mathrm{ml}$ ( $\left.\mathrm{p}_{\text {value }}\right) 0,847>0,05(\alpha=$ $5 \%$ ). Dari ketiga dosis tersebut setelah di uji menggunakan uji Anova One Way menunjukkan nilai $\mathrm{p}$ (sig) 0,539, yang artinya jika $p>\alpha$ maka $\mathrm{Ha}$ ditolak sehingga tidak ada pengruh pemakaian perasan akar rumput alang-alang (imperata cylindrica) sebagai handsanitizer terhadap penurunan angka kuman.

\section{B. Saran}

1. Sebaiknya untuk mengambil bahan kimia yang dapat digunakan sebagai anti bakteri terdapat pada akar rumput alangalang menggunakan teknik lain selain perasan, yaitu contohnya ekstraksi, Ekstraksi adalah suatu proses yang dilakukan untuk memperoleh kandungan senyawa kimia dari jaringan tumbuhan maupun hewan dengan pelarut yang sesuai dalam standar prosedur ekstraksi (ICS-UNIDO, 2008; Ditjen POM, 2000).

2. Peneliti selanjutnya sebaiknya menurunkan dosis perasan akar rumput alang-alang di bawah $5 \mathrm{ml}$ agar lebih efektif dalam menurunkan angka kuman pada tangan.

3. Sebaiknya cleaning service menggunakan sarung tangan dan mencuci tangan setelah bekerja dengan handsanitizer untuk mengurangi keberadaan angka kuman.

4. Peneliti selanjutnya sebelum pengaplikasian perasan akar rumput alang alang sebagai handsanitizer sebaiknya di sterilisasikan terlebih dahulu, agar tidak ada angka kuman di perasan akar rumput alang-alang.

\section{Daftar Pustaka}

Departemen Kesehatan, 2014, Pusat Data Informasi Kementerian Kesehatan RI Perilaku Mencuci Tangan Pakai Sabun di Indonesia, Jakarta at http://www.depkes.go.id/folder/ view/01/ structure-publikasi-pusdatin-infodatin.html Diakses pada Tanggal 18 Desember 2018 Pukul 12:47 WIB).

Masrur Puji Pangestu, 2013, Kefektifan Handrub dalam Menurunkan Angka Kuman di Rumah Sakit PKU Muhammadiyah Gombong Kabupaten Kebumen, Kesehatan Lingkungan. Poltekkes Kemenkes Semarang.

Raka Novadlu Cordita, 2017, Perbandingan Efektivitas Mencuci Tangan Menggunakan Hand Sanitizer Dengan Sabun Antiseptik pada Tenaga Kesehatan di ICU RSUD Dr. H. Abdul Moeloek, Kedokteran, Universitas Lampung at https:/ppjp.ulm.ac.id/journal /index.php/ JPKMI/article/view/5485/4632 Diakses pada Tanggal 03 September 2015 Pukul 17:16 WIB.

Fajar Ardi Desiyanto dan Sitti Nur Djannah 2013, Efektivitas Mencuci Tangan Menggunakan Cairan Pembersih Tangan Antiseptik (Handsanitizer) Terhadap Jumlah Angka Kuman, Kesehatan Masyarakat, Vol.7, No.2, September 2013 (03 Oktober 2018 Pukul 19:47 WIB).

Agus Priyanto, 2016, Perbandingan Tingkat Resistensi Handsanitizer Dengan Sabun Cuci Tangan Terhadap Bakteri yang Terdapat di Tangan, Keguruan dan Ilmu Pendidikan, Universitas Pasundan at http://repository.unpas.ac.id/12552/ Diakses pada Tanggal 07 Desember 2018 Pukul 15:31 WIB.

Fransisca dena, 2016, Kebersihan dan Kesehatan Tangan, http://tugastingkat1.blogspot.com/ 2016/03/kebersihan-dan-kesehatantangan.html, Diakes pada 13 Desember 2018 Pukul 20:14 WIB.

Tata Gunawan, 2014, Ciri Umum, Kandungan Kimia, dan Manfaat Alng-alang, http://tanamanobatherbalkeluarga.blogspot .com/2015/11/ciri-umum-kandungankimia-manfaat-alang-alang.html, Diakses pada 13 Desember 2018 Pukul 20:23 WIB.

Hadianti, 2014 , Triterpenoid, https://www.slideshare.net/fitri7827/triterp enoid, Diakses pada tanggal 13 Desember 2018 Pukul 21:00 WIB. 
Peraturan Menteri Kesehatan Nomor 3 Tahun 2014 tentang Sanitasi Total Berbasis Masyarakat, Jakarta.

Krisna Indra, 2015, Klasifikasi dan Morfologi Alang-alang, http://materipengetahuan umum.blog spot.com/2017/04/klasifikasidan-morfologi-alang-alang.html, Diakses pada 11 Desember 2018 Pukul 20:51 WIB.

Tri Cahyono, 2018, Panduan Penulisan Skripsi, Purwokerto: Politeknik Kesehatan Kemenkes Semarang Jurusan Kesehatan Lingkungan Purwokerto.

Djamaluddin Ramlan, 2013, Petunjuk Praktis Penulisan Penelitian Eksplanatif, Purwokerto: UPT Percetakan dan Penerbitan Universitas Jenderal Soedirman Purwokerto

Aris Santjaka, cetakan 1 2011, Statistik untuk Penelitian Kesehatan 1, Yogyakarta: Nuha Medika.

Retno Wuriyatmi, 2016, PerbandinganEfektifitas Handrub Septic Gel® dan Formula ${ }^{R w}$ Terhadap Penurunan Angka Kuman pada Tangan di RSUD Ajibarang Tahun 2016, Jurusan Kesehatan Lingkungan Poltekkes Kemenkes Semarang.

Peraturan Pemerintah Republik Indonesia Nomor 66 Tahun 2014 tentang Kesehatan Lingkungan, Jakarta.

Sudarminto Setyo Yuwono, 2015, Alang-alang (Imperata cylindrica), http://darsatop.lecture ub.ac.id/2015/10/alang-alang-imperatacylindrica/ Diakses pada Tanggal 03 September 2018 Pukul 21:31 WIB.

Machdika Tri Syavina, 2013, Faktor-faktor yang Berhubungan dengan Kelelahan Kerja pada Petugas Cleaning Service di RSUD Kota Semarang Tahun 2013, http:/leprints.dinus. ac.id/6494/2/abstrak_12422.pdf Diakses pada Tanggal 03 September 2018 Pukul 21:44 WIB.

Erina Setya Anggraeni, 2016, Perbedaan Pendidikan Kesehatan Metode Demonstrasi Secara Langsung Dengan Audio Visual Tentang Cuci Tangan Terhadap Praktek dan Perilaku Cuci Tangan Pada Usia Pra Sekolah,http://repository.ump.ac.id/810/3/ ERINA\%20SETYA\%20ANGGRAENI\%2
0BAB\%20II.pdf Diakses pada Tanggal 13 Desember 2018 Pukul 21:56 WIB.

Ade Novia Rezki, 2016, Perbandingan Daya Bunuh Produk Handsanitizer Gel Berbasis Alkohol dan Triclosan Terhadap Bakteri Tangan,

http://repository.unpas.ac.id/11571 15/Bab\%20II\% 20.pdf Diakses pada Tanggal 14 Desember 2018 Pukul 15:41 WIB.

Agustianty Nur Hapshahror, 2015, Aktivitas Antibakteri Ekstrak Etanolik Rumput Laut (Eucheuma cottoni Weber van-Bosse) Terhadap Klebsiella pneumoniae dan Pseudomonas aeruginosa, Jurusan Farmasi, Universitas Jendral Soedirman.

Azwar Agoes, 2010, Tanaman Obat Indonesia Buku 3, Jakarta: Salemba Medika.

Moh.Syafiq Arista, 2015, Efektifitas Antibakteri Infusa Biji Pepaya (Carica papaya Linn) Terhadap Bakteri Staphylococcus aureus, Escherichia coli dan Pseudomonas aeruginosa Secara In Vitro, http://digilib. unimus.ac.id/gdl.php? mod=browse \&op $=r$ ead\&id=jtptunimus- gdl-moh syafiqa-7277 Diakses pada Tanggal 11 Desember 2018 Pukul 22:27 WIB.

Ebta Setiawan, 2018, Kamus Besar Bahasa Indonesia tentang kuman, https://kbbi.web.id/kuman Diakses pada Tanggal 07 Desember 2018 Pukul 16:01 WIB.

Erwenda Panca dkk, 2015, Efektifitas Hand Soap dan Hand Sanitizer Terhadap Penurunan Angka Kuman pada Telapak Tangan Siswa/i Pengunjung Badan Perpustakaan Daerah Provinsi Kalimantan Timur, https://dspace.umkt.ac.id/bitstream/handle/ 463.2017/1038/ERWENDA\%20PANCA \%20NP.pdf?sequence $=1 \&$ isAllowed $=\mathrm{y}$. Diakses pada Tanggal 21 Mei 2019 Pukul 16:20 WIB.

Soedarto, 2015, Mikrobiologi Kedokteran, Jakarta:CV.Sagung Seto.

Ulya, 2019, Pengertian Ekstraksi Menurut Para Ahli, https://ulyadays.com/pengertianekstraksi-menurut-para-ahli/. Diakses pada Tanggal 12 Juni 2019 Pukul 16:43 WIB. 